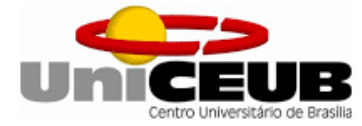

CENTRO UNIVERSITÁRIO DE BRASÍLIA - UniCEUB

FACULDADE DE CIÊNCIAS DA EDUCAÇÃO E DA SAÚDE - FACES PROGRAMA DE INICIAÇÃO CIENTÍFICA

ELLEN KARINE MARQUES RIBEIRO

PAINEL DAS MUTAÇÕES PARA AS SÍNDROMES

MIELOPROLIFERATIVAS

BRASÍLIA

2017 


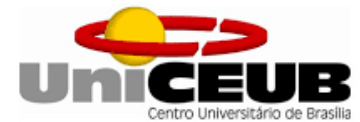

ELLEN KARINE MARQUES RIBEIRO

\title{
PAINEL DAS MUTAÇÕES PARA AS SÍNDROMES MIELOPROLIFERATIVAS
}

\author{
Relatório final de pesquisa de Iniciação \\ Científica apresentado à Assessoria de \\ Pós-Graduação e Pesquisa pela Faculdade \\ de Ciências da Educação e da Saúde - \\ Faces \\ Orientação: Graziela Silveira Araújo Alves
}

\section{BRASÍLIA}




\title{
PAINEL DAS MUTAÇÕES PARA AS SÍNDROMES MIELOPROLIFERATIVAS
}

\author{
Ellen Karine Marques Ribeiro - UniCEUB, PIC Institucional, aluno bolsista.
}

ellenribeiro37@gmail.com

\author{
Graziela Silveira Araújo Alves - UniCEUB, professor orientador. \\ graziela.araujo@uniceub.br
}

A complexidade e demora da caracterização diagnóstica para as Síndromes Mieloproliferativas Crônicas (SMPCs) fundamenta-se na semelhança clínicopatológica entre elas. Entretanto, a mieloproliferação das células tronco hematopoiéticas relacionada às SMPCs não deriva de uma mesma mutação para todos os casos, podendo ser estabelecido um grupo heterogêneo em relação aos marcadores moleculares, além da vantagem dessas alterações estarem presentes mesmo em fase precoce e na ausência de manifestações clínicas. Nesse intuito, os objetivos dessa pesquisa foram definir as principais mutações relacionadas às SMPCs, identificando o perfil clínico, fisiopatológico, laboratorial e molecular das desordens mieloproliferativas crônicas, a fim de elaborar um painel das mutações como ferramenta adicional para o diagnóstico das SMPCs. Este estudo foi realizado através de uma revisão bibliográfica em uma abordagem qualitativa e exploratória, tendo sido selecionados artigos nas línguas inglesa e portuguesa encontrados nas fontes indexadas: Scielo, Bireme, Medline, Pubmed, no período de 2000 a 2017, além de livros referência no assunto pertencentes ao acervo da biblioteca do Centro Universitário de Brasília (UniCEUB). A mutação mais prevalente entre as SMPCs é a que ocorre no gene Janus Quinase (JAK). Contudo, o atual marcador molecular mais relevante para o diagnóstico diferencial entre as SMPCs é a mutação que leva a fusão dos genes promotores BCR-ABL, dando origem ao cromossomo Philadélfia, característico da Leucemia Mielóide Crônica, a SMPC mais prevalente no mundo. Outras mutações com menor incidência podem ser identificadas entre as SMPCs, são elas: as associadas ao gene MPL (W515K, W515K e S505N); as mutações somáticas no gene caltireticulina (CARL); a mutação do gene supressor Ten Eleven Translocation 2 (TET2); a mutação associada a fusão dos genes FIP1L1-PDGFRA; e a mutação no códon D816V do gene KIT. Essas alterações gênicas são responsáveis por desencadear o processo fisiopatológico da proliferação dos componentes hematopoiéticos que, por vezes apresentam-se com pouca ou nenhuma diferença morfológica entre si. Por isso, a contribuição de tais marcadores moleculares vem sendo cada vez mais reconhecida para a caracterização das SMPCs, a ponto da presença de alguns deles já estarem sendo utilizados e citados como parte dos critérios diagnósticos pela Organização Mundial de Saúde. Acredita- se que outras mutações possam estar associadas às SMPCs visto a observação que ainda existem dentro deste grupo as Síndromes Mieloproliferativas Não-Classificáveis. Assim, pesquisas nessa temática devem ser incentivadas, todavia, fatores limitantes são levantados em questão como: o custo financeiro das técnicas moleculares e a raridade dessas síndromes, que associada a uma manifestação clínica em idade avançada, torna-se, muitas vezes, um fator impeditivo.

Palavras chaves: mieloproliferação; mutação, neoplasias hematológicas crônicas. 


\section{Sumário}

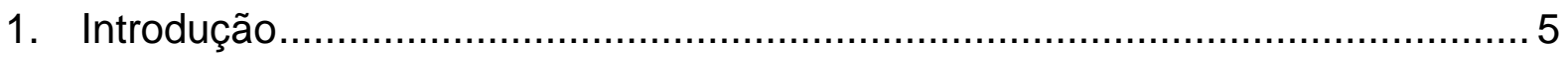

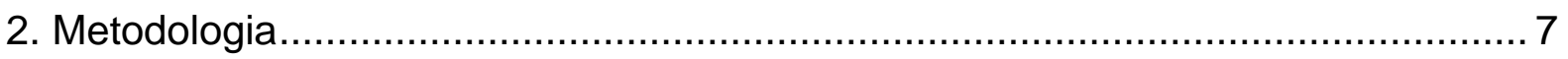

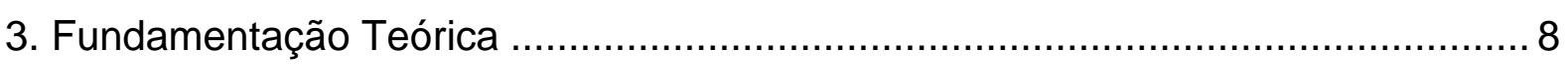

3.1 Síndromes Mieloproliferativas Crônicas (SMPCs).............................................. 8

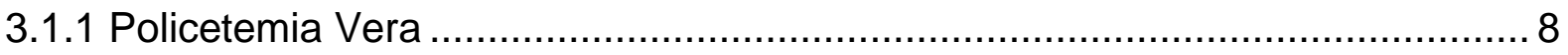

3.1.2 Mielofibrose Primária................................................................................ 10

3.1.3 Trombocitemia Essencial ..................................................................... 14

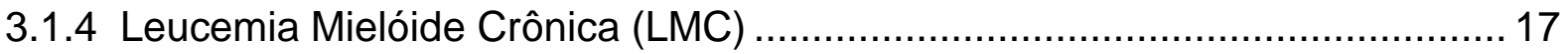

3.1.5 Leucemia Neutrofílica Crônica …………………................................... 19

3.1.6 Síndrome Hipereosinofilica Crônica ............................................................ 20

3.1.7 Leucemia Eosinofílica Crônica ................................................................ 20

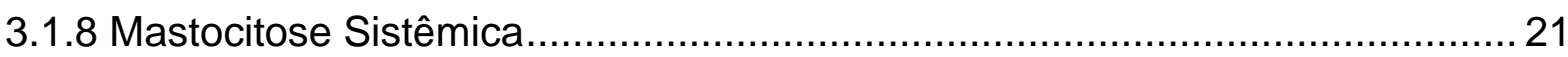

3.1.9 Síndromes Mieloproliferativas Não-Classificáveis (SMNC) ……................... 22

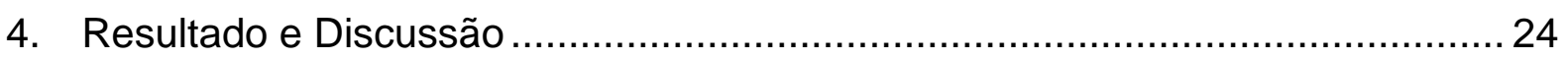

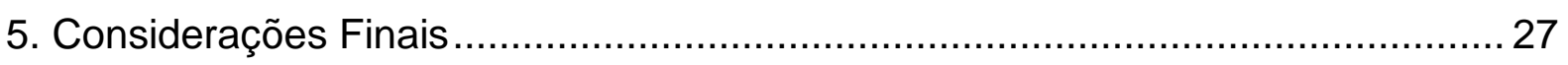

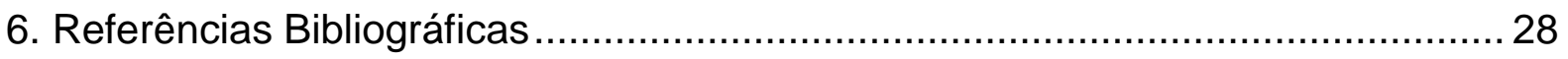

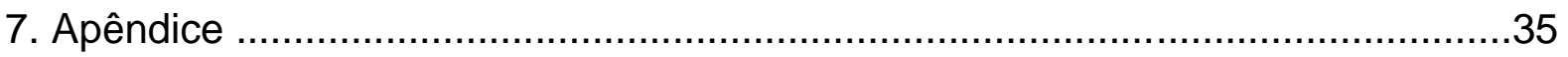

7.1. Apêndice 1 - Painel da mutações para as Síndromes Mieloproliferativas

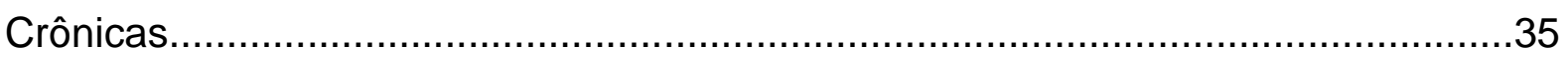




\section{Introdução}

William Dameshek, na década de 50 , foi o médico pioneiro do termo "síndromes mieloproliferativas" (SMPs) ao identificar que algumas neoplasias hematológicas (Policetemia Vera - PV, a Trombocitemia Essencial - TE, Mielofibrose Primária - MP, e a Leucemia Mielóide Crônica - LMC) derivavam de uma mieloproliferação celular da medula óssea (MO) com intensas características clínicopatológicas similares entre elas (TEFFERI, 2008). Em 2002, a Organização Mundial de Saúde (OMS) incluiu entre as SMPs, a Leucemia Neutrofílica Crônica (LNC), a Síndrome Hipereosinofílica Idiopática (SHI), a Leucemia Eosinofílica Crônica (LEC) e a Mastocitose Sistêmica (MS) (MONTE-MÓR; COSTA, 2008).

As SMPs são caracterizadas por proliferação clonal elevada de uma célula progenitora hematopoiética pluripotente, o progenitor mieloide. Esse aumento anormal pode ser oriundo de uma ou mais séries sanguíneas, envolvendo as linhagens eritrocitária, leucocitária e plaquetária (CHAUFFAILLE, 2010).

A etiologia dessas enfermidades vem sendo estudada há anos e propõe-se que há uma desregulação de genes específicos. Estudos genéticos e moleculares em busca por mutações em pacientes diagnosticados com PV, TE e MP mostraram que a maioria deles apresentavam uma alteração no alelo da proteína tirosina cinase Janus (JAK2). Essa mutação é caracterizada pela substituição de uma guanina em timina, resultando na mudança do aminoácido valina por fenilalanina no códon 617 da JAK2, sendo uma mutação adquirida (LEVINE; GILLILAND, 2016).

Assim, a presença da mutação da JAK2 (JAK2+) tem sido identificada como a principal alteração molecular para os pacientes com PV, MP e TE, contudo observase mecanismos fisiopatológicos distintos entre elas. A PV é caracterizada pela hiperproliferação clonal da linhagem eritrocitária que pode interferir ou não em outras linhagens. A MP apresenta um excesso de fibrose tissular na MO que, de forma avançada, a inabilita funcionalmente, levando a uma hematopoiese extramedular. Já a TE afeta a linhagem megacariocítica, com consequente aumento progressivo das plaquetas no hemograma (CAO et al., 2006; GRIESSHAMMER, 2006; NORD, 2012).

A LMC é uma doença mieloproliferativa JAK2 negativa que apresenta a formação de um novo cromossomo devido a fusão dos genes BCR-ABL, dando origem ao cromossomo nomeado de Philadelphia (Ph). Assim, trata-se uma entidade 
isolada dentro das SMPs por sua categorização distinta por meio de um cromossomo específico (INCA, 2003).

Outras mutações incluindo MPL, LNK, CBL, TET2, ASXL1, IDH, IKZF1, EZH2 e DNMT3A foram identificadas em subconjunto nos pacientes que apresentam Síndromes Mieloproliferativas Crônicas, porém o papel patogênico destes ainda se apresentam pouco esclarecidos (VARDIMAN, 2009). Recentemente, também foi relatado a fusão dos genes HBS1L/MYB que promovem efeito mais potente em casos de JAK2V617F- com associação da mutação na CARL e/ou no MPL. Já nos casos de JAK2V617+, a HBSL1/MYB se associa com TE e preferencialmente à PV. Sabe-se ainda que a expressão reduzida de MYB está previamente ligada ao desenvolvimento de uma doença semelhante a TE se associando com HBS1L/MYB em células mielóides normais. Outro gene diretamente relacionado as síndromes JAK2V617F negativas é o MECOM (TAPPER et.al, 2015).

Existem ainda as últimas SMPs incluídas pela OMS. Entre elas, a LNC que é extremamente rara e acomete a linhagem granulocítica, principalmente os neutrófilos, levando a um quadro laboratorial de neutrofilia no sangue periférico, que é sustentada por uma MO hipercelular e uma hepatoesplenomegalia (CHAUFFAILLE, 2010). A MS envolve a linhagem granulocítica por causa de uma massiva produção de mastócitos, sendo que alguns casos apresentam mutações associadas na JAK2, mas a mutação mais expressiva nos pacientes é no gene KIT (ANDRESEN et al., 2012). Já a LEC apresenta uma proliferação descontrolada dos precursores eosinofílicos, resultando em uma mieloproliferação persistente na $\mathrm{MO}$, tecidos e sangue periférico que tem sido associado à presença de anormalidades nos genes do receptor tipo alfa e beta para o fator de crescimento derivado de plaquetas (CHAUFFAILLE, 2010).

Existe ainda as Síndromes Mieloproliferativas Não-Classificáveis (SMNC) que são àquelas alterações neoplásicas que não se encaixam nas outras classificações (MOURA, 2012).

O objetivo dessa pesquisa foi definir as principais mutações relacionadas às Síndromes Mieloproliferativas Crônicas (SMPCs), promovendo o perfil clínico, fisiopatológico, laboratorial e molecular dessas desordens mieloproliferativas, a fim de estabelecer um painel das mutações como uma ferramenta auxiliar para o diagnóstico desse grupo de doenças. 


\section{Metodologia}

Este estudo foi realizado através de uma revisão bibliográfica em uma abordagem qualitativa e exploratória, tendo sido selecionados artigos nas línguas inglesa e portuguesa encontrados nas fontes indexadas: Scielo, Bireme, Medline, Pubmed, no período de 2000 a 2017, além de livros referência no assunto pertencentes ao acervo da biblioteca do Centro Universitário de Brasília (UniCEUB).

As palavras chaves utilizadas para busca foram: mutação, mieloproliferação, hiperceluridade medular, neoplasias hematológicas crônicas, Policetemia Vera, Trombocitemia Essencial, Mielofibrose Primária, Leucemia Mielóide Crônica, Leucemia Neutrofilica Crônica, Síndrome Hipereosinofilica Crônica, Leucemia Eosinofilica Crônica, Mastocitose Sistêmica, Síndromes Mieloproliferativas Não Classificáveis, BCR-ABL, JAK2, sendo utilizadas individualmente ou em combinação de duas a duas com o auxílio do conector "AND". 


\section{Fundamentação Teórica}

\subsection{Síndromes Mieloproliferativas Crônicas (SMPCs)}

A hematopoese padrão é policlonal e apta à diferenciação mielóide e linfóide. Contudo, na hematopoese em pacientes com doenças mieloproliferativas crônicas a produção é monoclonal, sendo resultante de um clone tumoral que mantém a capacidade de se diferenciar em células maduras e funcionais. A célula proveniente do clone maligno é a célula tronco hematopoética, que leva a proliferação de precursores anormais na medula óssea com capacidade de crescimento independente de citocinas e hipersensíveis aos diversos fatores de crescimento (TEFFERI, 2005; VASSALO, 2012).

\subsubsection{Policetemia Vera}

A Policetemia Vera (PV) é uma doença clonal do sistema hematopoético com proliferação das linhagens eritrocitária, granulocítica e megacariocítica, cuja manifestação mais eminente é o aumento da massa eritrocitária, com elevação persistente do hematócrito. Tem chances de evolução para mielofibrose, mielodisplasia, e leucemia aguda (BARBUI et.al, 2011; RIBEIRO et al., 2009). A poliglobulia característica desencadeada nessa síndrome é definida como o aumento contínuo do número de glóbulos vermelhos circulantes por um período superior a dois meses (LEE; ARCASORY, 2015).

As manifestações clínicas mais comuns são prurido, trombose, hemorragia, esplenomegalia e queixas neurológicas. Em 40\% dos casos, há relatos de prurido após o banho, provavelmente devido a liberação de histamina por basófilos e mastócitos. A eritromelalgia, evidenciada por dor e queimação nos dedos, é outra sintomatologia muito presente. Queixas neurológicas como escotomas, diplopia, vertigem e isquemias cerebrais transitórias também podem estar associadas ao diagnóstico, bem como algumas alterações vasculares, cefaleia, perda de peso, sudorese e dispneia (SPIVAK; SILVER, 2008).

Dados revelam que $30 \%$ dos pacientes apresentam trombose antes do diagnostico, além disso, todas as formas de tromboembolismo estão envolvidas. Pode ocorrer em $25 \%$ dos pacientes sangramentos leves, devendo-se levar em consideração as hemorragias gastrointestinais prolongadas que podem até mesmo 
mascarar o diagnóstico de PV e quadros cirúrgicos que podem culminar tanto em quadro de trombose quanto de hemorragias (GISP, 1995)). Dentre algumas doenças relacionadas à $\mathrm{PV}$ destacam-se a gota e úlceras, e a ocorrência da síndrome de Budd Chiari deve ser ponderada em pacientes com $\mathrm{PV}$, singularmente quando os pacientes apresentam ascite e alterações funcionais hepáticas (BUZZAS et al., 2009)

Idosos e indivíduos do sexo masculino são os mais acometidos pela PV, sendo estimado uma incidência de 0.8-2.6/100.000 casos (BOYIADZIS et al., 2007; AMARAL, 2009). É mais frequente na etnia caucasiana, sendo historicamente relatada entre judeus askenazi (CHAITER, 2009). Pacientes tratados possuem uma média de sobrevida entre 10 e 15 anos, porém, sem tratamento, a sobrevida cai para menos de 2 anos. Essa redução na expectativa de vida está associada aos riscos de complicações trombóticas e hemorrágicas em graus variados (BARBUI, 2011).

A PV gera uma celularidade medular elevada com maturação completa, podendo haver hiperplasia de mais de uma linhagem no sangue periférico. Predominantemente há uma contagem aumentada da linhagem eritrocitária proporcional à elevação do hematócrito, com presença de hemoglobina para homens superior a $18,5 \mathrm{~g} / \mathrm{dL}$ e para mulheres superior a $16,5 \mathrm{~g} / \mathrm{dL}$. Habitualmente, os pacientes apresentam o valor da massa eritrocitária acima de $25 \%$ do valor de referência (BOYIADZIS et al., 2007).

Há neutrofilia em $60 \%$ dos casos, casualmente com presença de células imaturas (mielócitos e metamielócitos) em sangue periférico. A basofilia é encontrada em dois terços dos casos, enquanto que as plaquetas se encontram aumentadas em $50 \%$ dos pacientes, podendo chegar a mais de 1 milhão $/ \mathrm{mm}^{3} \mathrm{em} 10 \%$ dos casos. (BOYIADZIS et al., 2007)

A produção de eritrócitos é controlada de forma estrita principalmente pelo hormônio eritropoetina (EPO). Processos patológicos que incitem o aumento dos níveis séricos de EPO podem levar ao surgimento de PV (JAMES et al., 2005).

Nesse contexto, a maioria dos casos de PV provém de uma mutação pontual que altera a codificação da proteína JAK2, uma tirosina quinase pertencente à família das Janus quinases, ocorrendo uma substituição de uma guanina por timina ( $G>T$ ) no éxon 14 do gene JAK. Esta mutação é somática, resultando em uma substituição de uma valina por uma fenilalanina $(V>F)$ na posição 617 da proteína codificada (JAK2V617F), sendo que todas as células descendentes herdarão a alteração com exceção da linhagem linfoide e células da mucosa bucal. Por ter características 
inespecíficas, ela tem um padrão heterogêneo capaz de formar colônias eritróides mesmo na ausência da eritropoietina (SPIVAK; SILVER, 2008).

A JAK2 quando fosforilada em resposta a diversas citocinas, ativa diferentes vias de sinalização intracelular e participa do processo de transdução de sinal. Contudo, a JAK2V617F na Policetemia Vera faz autofosforilação constitutiva de JAK2, fosforilação constitutiva do fator STAT5, além da indução de transcrição dependente de STAT5 na ausência de EPO (MONTE-MOR, 2008).

Há ainda o gene LNK (A300V, V402M, R415H), uma proteína adaptadora que rege negativamente a via de sinalização da JAK2/STAT. Foi observado sua correlação com as síndromes mieloproliferativas crônicas com a presença ou não da associação com a JAK2V617F (CHEN et al., 2016). Existem ainda outras mutações que podem levar a PV, como uma alteração no éxon 12 do JAK2, envolvendo substituição, duplicação e deleção de nucleotídeos (SPIVAK; SILVER, 2008).

Além da hiperproliferação da $\mathrm{MO}$, alguns pacientes possuem alteração cromossômica como: 20q-, trissomia dos cromossomos 8, 9 e 13q- (AMARAL, 2008; HAMERSCHLAK, 2008), podendo ser utilizados como marcadores citogenéticos como forma de diagnóstico complementar. A evolução da doença é heterogênea indicando a ocorrência de fenômenos adicionais, expandindo-se a instabilidade genômica e promovendo a leucemogenese. É relatado duas formas de progressão da síndrome, a primeira leva a LMA na qual uma determinada classe de mutação leva vantagem proliferativa (JAK2V617F) e na segunda ocorre o bloqueio de diferenciação hematopoetica (deleção 20q) (RIBEIRO et al., 2009).

O diagnóstico para a PV é obtido por meio de critérios de exclusão, sendo identificados como maiores e menores. Os critérios maiores são: cariótipo anormal, dosagem de hemoglobina elevada, presença de JAK2 V617F ou mutação similar, total de hemácias com $25 \%$ acima do valor de referência. E os critérios menores são: hiperplasia das três linhagens na medula óssea, eritropoetina sérica acima do normal, presença de colônia eritróide endógena crescida. Para fechamento do diagnóstico torna-se necessário a presença de dois critérios maiores e um critério menor, ou um critério maior e dois critérios menores (BOYIADZIS et al., 2007; AMARAL, 2008).

\subsubsection{Mielofibrose Primária}

A Mielofibrose Primária (MP), doença mieloproliferativa crônica que possui cromossomo Philadelphia negativo, é uma neoplasia que afeta as células-tronco 
hematopoiéticas com alterações no estroma medular, ocasionando a formação de fibrose e angiogênese. É caracterizada por graus variados de fibrose na medula, hematopoese extramedular, hepatoesplenomegalia e presença de dacriócitos no sangue, também podendo ser chamada de metaplasia mielóide agnogênica, mieloesclerose, metaplasia mielóide idiopática e esterosclerose (MOURA, 2012; ZAGO et al., 2013).

A enfermidade possui duas fases: a pré-fibrótica com MO hipercelular e proliferação da linhagem megacariocítica sem que ainda possua a presença de fibrose, e a fase fibrótica quando ocorre uma substituição quase total do tecido medular por fibras de reticulina. Aproximadamente $15 \%$ dos pacientes evoluem para a Leucemia Mielóide Aguda (LMA), infecção e sangramento em estágios mais avançados da síndrome (NORD, 2012).

Ao diagnóstico, 25\% dos pacientes são assintomáticos, mas se sintomáticos apresentam sintomas secundários como: anemia, sudorese noturna, dispneia, febre, dor óssea, sangramento, hipertensão portal e perda de peso. É comum sintomas associados a falência medular, hemorragias, infecções e intolerâncias a esforços, resultante da anemia. Podem ocorrer também por conta da hiperuricemia, gotas e cálculo renal (CHAUFFAILLE, 2010).

Em $90 \%$ dos pacientes há a presença de esplenomegalia, enquanto que a hepatomegalia ocorre em somente $50 \%$ dos casos, porém, na fase pré-fibrótica somente $15 \%$ dos pacientes apresentam esplenomegalia. Durante o percurso da doença, os pacientes apresentam complicações secundárias decorrentes da pancitopenia, como sangramentos, infecções, hipertensão portal decorrente do fluxo esplenoportal aumentado, ocorrendo em $17 \%$ dos pacientes. É comum em pacientes com uma alta necessidade transfusional a aparição de hemossiderose, levando a aparição de insuficiência cardíaca e arritmias. Em $1 \%$ dos pacientes pode se transformar em leucemia aguda (BAROSI et al., 2001; ARORA, 2005).

No estágio pré-fibrotico os achados laboratoriais são característicos de doença mieloproliferativa crônica podendo incluir anemia leve, leucocitose leve a moderada, e plaquetose. Podem estar inclusos dacriócitos, plaquetas atípicas e megacariócitos circulantes em pequeno número. Usualmente a medula óssea se encontra hipercelular com proliferação granulocítica com importante desvio a esquerda, e possibilidade de eosinofilia e basofilia. A proliferação megariocítica é qualificada por crescimento anormal e localização trabecular, sendo que os megacariocitos 
apresentam morfologia atípica, com elementos imaturos que podem ser gigantes ou micromegacariócitos atípicos. É mínima ou ausente a fibrose reticulínica nessa fase (BAROSI et al, 2001).

No estágio fibrótico, a fibrose vai levando a insuficiência da medula óssea progressivamente. Observa-se anemia importante e contagens granulocíticas e plaquetárias reduzidas, normais ou amentadas com função anormal dos neutrófilos. Reação leucoeritroblástica é ressaltante, com presença de precursores ganulocíticos e eritrocíticos em sangue periférico, além das hemácias com formatos alterados (dacriócito e poiquilócito). A série plaquetária é indicada por megacariócitos no sangue, podendo apresentar plaquetose ou plaquetopenia, com função celular alterada (CHAUFFAILLE, 2010).

A presença de $10 \%$ a $19 \%$ de blastos no sangue periférico ou na medula óssea demarca a MF de fase acelerada, e a presença de $20 \%$ de blastos delimita a conversão para leucemia aguda secundária. A medula óssea normalmente é normo a hipocelular. Dessa forma, há fibrose reticulínica progressiva e perda progressiva dos componentes hematopoéticos, sucedendo na presença de somente alguns agregados de megacariócitos atípicos no meio da fibrose reticulínica ou de colágeno (MARTINS et al., 2016).

Essa doença tem uma incidência baixa de aproximadamente $0,5-1$ casos por 100.000 habitantes/ano, com predominância no sexo masculino e idade de 60 anos, tendo uma sobrevida de 3 a 10 anos (AHMED, CHANG, 2006; REILLY, 2006).

A causa excessiva de fibrose na medula óssea ainda não é bem elucidada, contudo, sabe-se que plaquetas, megacariócitos e monócitos clonais secretam citocinas, como TGF-beta, bFGF, EGF e PDGF, que muito provavelmente ocasionam a proliferação de fibroblastos não clonais, musculares lisas e mesenquimais com desregulação da formação da matriz extracelular. Uma vez dentro dos megacariócitos, os neutrófilos liberam enzimas proteolíticas, resultando na morte de ambas as células, com liberação de TGF-beta, e PDGF dos alfas grânulos dos megacariócitos. O TGF-beta eleva os níveis de fibronectina e colágenos do tipo I, III e IV, assim como a expressão de condroitina, dermatan sulfato e proteoglicanos (SCHMIT et al., 2002; TEFFERI, 2005; BAROSI, 2005).

Uma característica importante da MP é a neo-angiogênese que ocorre como resultado da produção e liberação de fatores angiogênicos. A localização anormal de células hematopoéticas é observada pelo aumento de células CD34+, marcador 
fenotípico de células tronco e progenitores hematopoéticos na circulação. O CD34 é expresso em $1 \%$ a $3 \%$ das células da medula óssea e em $0,05 \%$ das células do sangue periférico. Porém na MP, enzimas proteolíticas levam a clivagem de moléculas e consequente à mobilização das CD34+ para a corrente sanguínea. $\mathrm{Na}$ MP há expansão da hematopoese na cavidade central da medula e extensão para sítios extramedulares, ocorrendo a ativação de células tronco dormentes do baço e do fígado desde a vida fetal. Embora a presença de um número elevado de CD34+ circulante ser especifico para MP, esse dado não é muito sensível, uma vez que existem pacientes com MP que não apresentam essa característica. Ademais ocorre a presença de células progenitoras endoteliais na circulação, que expressam CD34, CD133, VEGFR2 e podem ser detectadas em cerca de $50 \%$ dos pacientes portadores de MP (MARTYRE, 1997; JANOWSKA-WIECZOREK, 1999; DI RAIMONDO, 2001; $X U, 2005)$.

Dentre os achados laboratoriais para a MP pode haver presença de eritroblastos em sangue periférico e hiperplasia megacariocítica atípica na medula óssea, sendo que as alterações variam de acordo com a fase ao qual o paciente se encontra. O estágio pré-fibrótico acomete $20 \%$ a $25 \%$ dos casos, enquanto o estágio fibrótico está presente em $70 \%$ a $80 \%$ dos pacientes (BAROSI et al., 2001).

A fibrose presente na MP é adquirida por causa da proliferação clonal que eleva a quantidade de megacariócitos, aumentando a liberação de fator de crescimento fibrogênico. A explicação da proliferação em aproximadamente $1 / 2$ dos casos é devida a mutação JAK2V617F. Outras mutações como a W515K do gene MPL, receptor da trombopoetina, em pacientes JAK2 negativa já foram relatadas Mutações somáticas da caltireticulina (CARL) incluindo deleções ou exclusões estão presentes em $20 \%$ a $25 \%$ dos casos (MONTE-MÓR; COSTA, 2008).

Anormalidades cromossômicas também podem ser detectadas na metade dos pacientes portadores da MP, porém nenhuma alteração especifica foi detectada. Dentre as mais comuns anormalidade encontradas, se incluem del (13) (q13;q22), del (20) (q11;q13), trissomia parcial do $1 \mathrm{q}$ e trissomia do 8. Anormalidades dos cromossomos 7, 9 e 12 também são encontradas. Estudo recente sugere que del (6) $\mathrm{t}(1 ; 6)$ (q21-23;p21.3) são patognomônicos da MP. Deleções do 5 e 7 podem ocorrer, mas sua ocorrência é sugestiva de uso prévio de agentes citotóxicos. Em $90 \%$ dos pacientes no momento da transformação leucêmica apresentarão alterações cromossômicas (NANGALIA et al., 2012; LASHO et al., 2012). 
Os critérios maiores para o diagnóstico de MP são: $1^{\circ}$ ) presença de proliferação megacariocítica com elementos atípicos, usualmente acompanhada de fibrose reticulínica ou de colágeno. Na ausência de fibrose significativa, as alterações megacariocíticas devem ser acompanhadas por aumento da celularidade da medula óssea caracterizada por proliferação granulocítica e, frequentemente, redução da eritropoese; $2^{\circ}$ ) ausência de critérios para PV, LMC com BCR/ABL negativas, TE, mielodisplasias e outras neoplasias mielóides; 3ํ) presença da JAK2 ou outro marcador clonal como a W515K ou, na ausência de marcadores, a não evidência de fibrose medular reacional. Os critérios menores são eles: leucoeritroblastose, aumento de LHD, anemia, esplenomegalia palpável. O diagnóstico requer 3 critérios maiores e 2 menores (BOYIADZIS et al., 2007).

\subsubsection{Trombocitemia Essencial}

A Trombocitemia Essencial (TE) é uma doença proliferativa clonal BCR/ABL1negativa que envolve principalmente a linhagem megacariocítica, com alterações que podem ser quantitativa e/ou qualitativa. É caracterizada por trombose sustentada em sangue periférico, aumento do número de megacariócitos maduros e grandes na medula óssea, e clinicamente quadros de trombose e/ou sangramento e fenômenos vasomotores (ZAGO et al., 2013).

De acordo com a OMS, a TE é definida como plaquetose persistente, superior a $600.000 / \mathrm{mm}^{3}$, e hiperplasia megacariocítica na medula óssea. É associada a eventos tromboembólicos graves gerando uma expectativa de vida em torno 22,6 anos. A incidência é de 1 a 2 casos a cada 100.000 habitantes/ano, relativamente maior em mulheres, e com idade média de diagnóstico entre 60 a 65 anos (JOHANSSON, 2006; GRIESSHAMMER et al., 2007).

Os principais sintomas clínicos são cefaleia, dor torácica, síncope, alterações na visão, esplenomegalia, atrofia esplênica, eritromegalia, livedo reticular, hemorragia e trombose (ZAGO et al., 2004). Um número significativo de pacientes apresenta-se assintomáticos e tendem a manter-se desta forma até o diagnóstico da TE. Já os pacientes sintomáticos têm quadros clínicos caracterizados pelas complicações trombo-hemorrágicas. Ao diagnóstico, 11 a $25 \%$ dos pacientes são diagnosticados com trombose, principalmente arteriais. A localização dos maiores eventos trombóticos com principal causa de mortalidade da TE são as grandes artérias, causadoras de complicações neurológicas e cardíaca. Manifestações hemorrágicas 
são visualizadas somente entre 2 a $5 \%$ dos pacientes no momento do diagnóstico e durante a evolução clínica nota-se em 1 a $7 \%$ dos casos. Esplenomegalia é encontrada ao apalpamento em 25 a 48\% dos pacientes (TEFFERI, 2005).

Outra situação que apresenta grande risco são as tromboses venosas profundas que podem evoluir para embolia pulmonar ou ocorrerem nas cavidades abdominais, levando em $10 \%$ dos pacientes à trombose da veia porta ou síndrome de Budd-Chiari. Eventos vaso-oclusivos mediados por plaquetas levam a uma gama de sintomas decorrentes da interrupção transitória da circulação. Pode ocorrer na TE um distúrbio circulatório característico chamado eritromelalgia, no qual o paciente apresenta queimações e ulceração dos dedos, com presença de extremidades quentes, ruborizadas e congestas. Esses processos isquêmicos digitais podem evoluir para necrose ou gangrena periférica com pulsos arteriais palpáveis. Episódios de dor de cabeça são comuns, bem como ataques isquêmicos típicos e atípicos com presença de crises convulsivas. A intensidade da plaquetose é um fator determinante para os eventos trombóticos (TEFFERI, 2005; BRIÈRE, 2007).

Quadros hemorrágicos se restringem a sangramentos mucocutâneos (epistaxe, gengivorragia, melena e hematêmese) e ocasionalmente com petéquias. Os sangramentos mais comuns são encontrados em pacientes que apresentam contagem de plaquetas superior a 1.000.000/ $\mu \mathrm{L}$ ou estão em uso de AAS, em pacientes com leucócitos acima de 11.000/ $\mathrm{L}$ e nos pacientes com história prévia de sangramentos. Cirurgias e traumatismos influenciam na ocorrência de sangramentos, de forma contrária, quando existem medidas preventivas adequadas raramente são visualizados. Pacientes com TE na gravidez apresentam riscos relativamente maiores quando comparado a uma gravidez normal. Observa-se a redução da contagem de plaquetas a partir do primeiro trimestre gestacional, o feto corre um maior risco pelo retardo do crescimento intrauterino, parto prematuro e placenta prévia (BRIÈRE, 2007; MICHIELS et al., 2006).

Muitos fatores estão associados a um maior risco e prognóstico desfavorável como: idade superior a 60 anos, eventos trombóticos/hemorrágicos prévios, tabagismo, hiperlepemia, diabetes melitos, hipertensão arterial, presença de anticorpos fosfolípides (particularmente os da classe $\lg \mathrm{M}$ ), hematopoese monoclonal, medula óssea com características atípicas, redução da concentração de eritropoetina e heterozigose para fator V Leiden (MARTINS et al., 2016). 
Ainda não se sabe com certeza qual o mecanismo desencadeante para a TE, contudo, percebe-se a relação entre a superprodução de megacariócitos e a trombopoetina. Este hormônio atua na MO produzindo e maturando o megacariócito, desencadeando uma plaquetose se liberado em excesso (GRIESSHAMMER, 2007).

A TE apresenta em 50\% dos casos a mutação JAK2V617F (BITTENCOURT, 2010). Ainda é incompreensível como uma mesma mutação é capaz de ocasionar diferentes fenótipos e prognósticos. Acredita-se que uma possível explicação seria 0 grau de expressão da mutação JAK2V617F, determinados polimorfismos genéticos e fatores epigenéticos, assim como outras mutações somáticas adicionais que ainda não foram detectadas e determinadas condições fisiológicas do indivíduo como a biodisponibilidade de ferro (CERVANTES, 2011; VAKIL et.al, 2011; VAINCHENKER et al., 2011; BEER, 2011).

Outras mutações estão associadas à TE como àquelas descritas no gene MPL (BITTENCOURT, 2010). Esse gene está associado ao receptor de trombopoetina e está presente em casos de JAK2V617F negativo, apresentando certa vantagem quanto a proliferação celular. A mutação no códon 515 do MPL (W515L, W515K, S505N) esclarece o defeito nas vias de sinalização das moléculas STAT3, STAT5, na proteína ativadora do mitogênio (MAPK) e na fosfatidil-3 kinase ATK (PI3K/AKT), disponibilizando ganho de função e uma vantagem mieloproliferativa aos megacariócitos. Outro afetado é o gene supressor Ten Eleven Translocation 2 (TET2), encodado no cromossomo 4, pode sofrer mutações ou deleções em $12 \%$ dos portadores de SMP. Um rearranjo no cromossomo 4q24 é promovedor de mutação somática no gene supressor TET2 em progenitores ainda não maturados (BITTENCOURT, 2010).

Existem outros genes associados na progressão neoplásica da TE, são eles: mutação do gene SESN2 (P87S) que pode levar a danos no DNA e causar instabilidade genética; mutação a do gene NTRK1 (N323S) um conhecido oncogene que quando alterado pode contribuir para a angiogênese sustentada e proliferação celular; mutação do gene ST13 (Q349*) que codifica uma proteína que interage com Hsc70 que controla a atividade de proteínas reguladoras, como receptores de esteróides e reguladores de proliferação ou apoptose; mutação do gene ABCB5 (G365V) cuja regulação se mostrou responsável por resistência a várias drogas em diferentes canceres, e outras alteração já relacionadas porém com nenhuma 
elucidação da fisiopatologia, como as associadas aos genes FRG1 (C205Y), ASNS (D118V), TOP1MT (S479L) e DNAJC17 (A292P) (HOU et al., 2012).

Os critérios para diagnóstico da TE são baseados em: persistência de plaquetas superiores a $450.000 \mu \mathrm{L}$ no hemograma, biópsia de medula óssea apresentando particularmente a proliferação da linhagem megacariocitária com número aumentado de megacariócitos grandes e maduros, ausência de critérios para diagnóstico de PV, MP, LMC e Síndromes Mielodisplásicas (ausência de eritropoese ou disgranulopoese), ou ainda outra neoplasia mieloide, e presença da mutação JAK2V617F ou outro marcador clonal, na ausência de marcadores clonais. Além disso deve ser verificado a ausência de trombocitose reacional (inexistência de causas reacionais de trombocitose, como ferropenia, esplenectomia, cirurgia, infecção, inflamação, colagenoses, neoplasia metastática e doenças linfoproliferativas) (ZAGO et al., 2013).

\subsubsection{Leucemia Mielóide Crônica (LMC)}

Em 1960, foi descrita pela primeira vez a translocação entre os cromossomos 9 e 22, dando origem a um cromossomo anormal chamado de cromossomo Philadelphia $(\mathrm{Ph})$, primeiro cromossomo identificado com doença específica no câncer (HAMERSCHLAK, 2008). Dos pacientes diagnosticados com LMC, mais de 90\% apresentam o cromossomo $\mathrm{Ph}$, formando o gene BCR-ABL (CHAUFFAILLE, 2008).

A LMC é uma doença clonal que afeta a produção de células hematopoiéticas, proporcionando uma hiperproliferação da linhagem mielóide (INCA, 2003). Nessa doença são identificadas três fases características. A primeira é conhecida como fase crônica que apresenta duração entre 2 e 7 anos, com sintomatologia de fadiga, febre, esplenomegalia, perda de peso, hemorragia e sudorese. Contudo, há possibilidade do paciente se encontrar assintomático (ZAGO et al., 2004).

A fase acelerada possui um período variável tendo aumento de blastos tanto na MO como no sangue, leucocitose e basofilia, além de diminuição das plaquetas e da hemoglobina. As manifestações clínicas são esplenomegalia, fibrose medular, febre, sudorese noturna, emagrecimento e dor óssea. Quando se compara sua evolução clonal com a fase crônica, há presença de hiperproliferação celular e as plaquetas encontram-se abaixo de 100.000/mm³ (MARTINS, 2016). 
A última fase chama-se crise blástica, no qual o paciente apresenta uma sobrevida pequena, pois o quadro clínico é muito agudo. Ao fazer a análise hematológica, nota-se a presença de infiltrado extramedular de células blásticas com presença dessas células superior a $20 \%$ na medula óssea ou no sangue periférico, no qual $50 \%$ dos casos são mieloblastos. Com sintomatologia característica de febre, astenia, emagrecimento, hemorragia e anemia severa (HAMERSCHLAK, 2008).

A incidência da LMC é de 1-2 casos a cada 100.000 habitantes/ano, com predominância no sexo masculino, sendo normalmente detectada aos 55-60 anos (BORTOLHEIRO; CHATTONE, 2008). Fatores como idade, grau de esplenomegalia, porcentagem de blastos, basófilos e número de plaquetas, podem interferir na evolução da doença e nortearão o tratamento que deverá ser proposto ao paciente (ZAGO et al., 2013; MARTINS, 2016).

Utilizam-se exames hematológicos, citogenéticos, moleculares e clínicos para determinar o diagnóstico de LMC. O hemograma encontra-se habitualmente com presença de hiperplasia mielóide, leucocitose, neutrofilia, basofilia e anemia normocítica e normocrônica. No exame citogenético é realizado a cariotipagem, procurando presença do cromossomo $\mathrm{Ph}$ e na pesquisa pela técnica de biologia molecular buscar-se identificar o gene híbrido BCR-ABL. Enquanto no exame clínico, a presença de esplenomegalia é essencial (INCA, 2003).

Este gene produz uma proteína que possui atividades semelhantes a tirosino quinase que tem poder de regular a proliferação celular. $O$ gene BCR tem três pontos de quebras. $O$ gene hibrido presente na $L M C$ é derivado da divisão do BCR em um local chamado maior (M-bcr). A transcrição deste gene gera moléculas de mRNA que fusiona o BCR/ABL com a junção dos exons b3a2 e ou b2a2. O resultado final deste produto é uma proteína de fusão citoplasmática $210 \mathrm{kDa}$ (p210) a qual carrega a responsabilidade pela repercussão clínica da LMC. A p210 tem autonomia de ativação e interfere na transdução de sinal dos processos celulares básicos, como aderência, proliferação e apoptose. A quebra BCR do segmento menor (m-bcr), de localização e1 e fusão com o $A B L$ no exon 2 forma uma proteína, que geralmente é associada a LMA porém em raros casos pode ser expressa em baixos níveis junto com a p210 na LMC. Já a quebra da região denominada micro $(\mathrm{u}-\mathrm{BCR})$ localizada no exon 19, com segmento a2 no $A B L$, produz uma proteína que tem sido descrita em casos de leucemia neutrofilica crônica com cromossomo Philadelphia (ZAGO et al., 2013). 
Outra mutação recentemente associada a LMC é a do gene LNK cujo severo polimorfismo pode agravar o caso clinico ou a predisposição genética para desencadear outras SMPCs (CHEN, 2016).

\subsubsection{Leucemia Neutrofílica Crônica}

A Leucemia Neutrofília Crônica (LNC) é uma síndrome mieloproliferativa que acomete a linhagem granulocítica, principalmente, os neutrófilos, causando uma neutrofilia severa em sangue periférico e uma leve leucocitose (CHAUFFAILLE, 2010).

A LNC acomete mais homens e pessoas idosas ao diagnóstico (QUINTERO, 2004; SOUTO, 2008). Suas manifestações clínicas possuem um curso lento e progressivo levando a uma esplenomegalia, hepatomegalia, sangramento mucoso ou do trato gastrointestinal, podendo apresentar febre, gota e prurido. Devido a progressão indolente da neoplasia, o diagnóstico pode ser realizado em fase tardia gerando uma sobrevida de 6 meses. Contudo, ao se diagnosticar precocemente a doença, a sobrevida é de até 20 anos (CHAUFFAILLE, 2010).

O predomínio são de neutrófilos maduros, superior a $80 \%$ dos granulócitos, sendo considerado raro ou ausentes a presença de células imaturas. O exame clinico é comumente normal e, raramente discreta esplenomegalia pode estar presente. É normal ou elevada a fosfatase alcalina dos leucócitos. O ponto de quebra do cromossomo Ph é diferente da LMC clássica (e19a2;p230) (ZAGO et al., 2013). Em $10 \%$ dos casos apresenta alterações cromossômicas. Os demais casos ainda não foram totalmente elucidados, tendo o diagnóstico a partir de exclusão pelos demais critérios das outras SMPs (SOUTO, 2008).

Entre as alterações laboratoriais em pacientes com LNC destaca-se uma leucocitose superior a $25.000 / \mathrm{uL}$ com $80 \%$ composto por segmentados e bastões, ( $<10 \%$ de granulócitos imaturos e $<1 \%$ de mieloblastos). A série vermelha apresenta morfologia normal na maioria dos casos (SOUTO, 2008). O cariótipo pode apresentar alterações, dentre elas as mais comuns são anormalidades nos cromossomos 8, 9 , del (20q), del (11q) (CHAUFFAILLE, 2010a).

Para essa desordem é feito a partir de critérios de exclusão que se seguem: biópsia da MO para avaliação da hipercelularidade, hepatoesplenomegalia, ausência de causa fisiológica para a neutrofilia (infecção, inflamação ou tumores), inexistência do rearranjo PDGFRa, PDGFRß ou FGFR1, sendo os três últimos presentes também 
na LEC; ausência de evidências para PV, MP, TE e para síndromes mielodisplásicas (QUINTERO, 2004). Biopsia de medula óssea hipercelular com aumento absoluto de granulócitos, mieloblastos e menos de $5 \%$ de células com núcleos na $\mathrm{MO}$, padrão normal de maturação dos neutrófilos, presença de megacariócitos normais ou com possível desvio a esquerda (CHAUFFAILLE, 2010b).

\subsubsection{Síndrome Hipereosinofilica Crônica}

A Síndrome Hipereosinofílica Crônica (SHC), também conhecida como Síndrome Hipereosinofílica Idiopática (SHI), é uma síndrome rara e sua causa relatada é uma mutação em células precursoras multipotentes que levam ao aumento descontrolado da produção de eosinófilos gerando uma infiltração nos tecidos (SANTOS,2008; DUARTE et al., 2012).

Nessa neoplasia ocorre uma predileção pelo sexo masculino, sem causa aparente. Acredita-se que a fusão gênica FIP1L1-PDGFRA leva a ativação da sinalização para a desordem mieloproliferativa sem outra causa conhecida, sendo 0 seu diagnóstico realizado na prática clínica por meio de exclusão das demais síndromes (JUNIOR, 2010).

Contudo, os critérios estabelecidos para o diagnóstico da SHC são: contagem de eosinófilos $>1500 / \mathrm{mm}^{3}$ por no mínimo 6 meses, lesão orgânica, ausência de outra causa para eosinofilia no sangue periférico (CHUSID; DALE; WOLF, 1975). Além desses, outras achados laboratoriais que podem auxiliar na identificação incluem uma contagem total de leucócitos acima de $30.000 / \mathrm{mm}^{3}$ com presença de $30 \%$ a $70 \%$ de eosinófilos, anemia, trombocitopenia, leucopenia, lesão cardíaca e tosse seca crônica persistente (CHUSID; DALE; WOLF, 1975; JUNIOR, 2010).

\subsubsection{Leucemia Eosinofílica Crônica}

A Leucemia Eosinofília Crônica (LEC) é uma síndrome clonal com proliferação descontrolada dos precursores eosinofílicos que levam a uma mieloproliferação persistente na $\mathrm{MO}$, tecidos e sangue periférico. A lesão orgânica nos tecidos ocorre devido a uma infiltração leucêmica, a partir da liberação de citocinas, enzimas ou demais proteínas pelos eosinófilos (CHAUFFAILLE, 2010; EUROPEAN UNION, 2016).

As causas que levam a LEC são anormalidades nos genes do receptor tipo alfa e beta para fator de crescimento derivado de plaquetas (PDGRFa e PDGFRß) ou 
receptores de fator de crescimento de fibroblastos (FGFR1), sendo que o rearranjo mais frequente é a partir da deleção do gene $\mathrm{CHIC2}$ ocasionando a fusão de fatores (FIP1L1/PDGRFa). Outra fusão com importante relevância é a PDGFRB-ETV6 (COOLS et al., 2003).

A LEC acomete mais os homens, com maior incidência ao redor dos 40 anos. Cerca de $10 \%$ dos pacientes são diagnosticados ao acaso por serem assintomáticos. Os demais possuem uma manifestação clínica que incluem febre, fadiga, angioedema, dores musculares, diarreia, anemia e esplenomegalia (CHAUFFAILLE, 2010).

Geralmente o diagnóstico ocorre a partir da exclusão de eosinofilia secundária causada por infecções parasitárias ou processos alérgicos; ausência do cromossomo $\mathrm{Ph}$ e do rearranjo BCR-ABL; observação de eosinofilia persistente; presença dos rearranjos envolvendo PDGFRa, PDGFRß ou FGFR1 e infiltração orgânica pelos eosinófilos ou mastócitos (CHAUFFAILLE, 2010a; CHAUFFAILLE, 2010b).

\subsubsection{Mastocitose Sistêmica}

A Mastocitose Sistêmica (MS) é uma proliferação clonal de mastócitos que infiltram os tecidos liberando seus mediadores inflamatórios (FERNANDES et al., 2002). É caracterizada por atingir outros órgãos, além do tecido epitelial, podendo haver seu comprometimento ou não. Os órgãos atingidos são a medula óssea, trato gastrointestinal, linfonodos e baço (MALUF; BARROS; FILHO, 2009).

Esta síndrome ocorre frequentemente em adultos e as manifestações clínicas são prurido, urticária, angioedema, rubor, vômitos, dor abdominal, diarreia, podendo chegar à anafilaxia (FERNANDES et al, 2002).

Sabe-se que o receptor tirosina quinase (c-kit) e o gene SCF possuem grande importância para o desenvolvimento e diferenciação dos mastócitos. Anormalidades no c-kit ou no gene do SCF trazem deficiências nos mastócitos, assim como outras mutações no c-kit protooncogene levam ao acréscimo do tempo de vida médio dessas células e de seus progenitores. Nota-se a existência das tirosinas quinases Lyn e Fyn, que regulam o sinal da transdução mastocitária, inibindo e estimulando a degranulação, respectivamente. Assim, a mutação característica da MS ocorre no códon D816V do gene KIT. Ela é detectada na maior parte dos pacientes, evidenciando sintomatologia da doença com ausência de lesões cutâneas e com biópsia medular normal (MALUF; BARROS; FILHO, 2009). 
No início da investigação da MS, o hemograma completo deve ser solicitado em intervalos curtos quando há suspeita de envolvimento sistêmico. Outros exames são necessários conforme a apresentação clínica do paciente, como ultrassom de abdome; densitometria óssea no caso de dor óssea no adulto; mielograma caso haja alterações como anemia, leucocitose persistente, eosinofilia inexplicada, dor óssea, hepatoesplenomegalia ou linfadenomegalia. É necessário a dosagem bioquímica para avaliar a triptase sérica que pode se apresentar normal ou levemente aumentada (GRATTAN, 2004).

Pacientes com suspeita de mastocitose na ausência de lesão cutânea devem ser submetidos à biópsia e a aspirado de medula óssea para diagnóstico e caracterização do subtipo da doença. $O$ exame de urina de 24 horas, com a dosagem do ácido 5-hidroxindolacético e das metanefrinas, ajuda a descartar a possibilidade de tumor carcinoide ou feocromocitoma na investigação da mastocitose. Níveis elevados de histamina, tanto urinária quanto plasmática, auxiliam no diagnóstico de mastocitose sistêmica com envolvimento difuso, especialmente quando há sintomas gastrointestinais. A dosagem dos mediadores liberados pelos mastócitos também pode ser útil para demonstrar atividade da doença (METCALFE et al., 2003; PRENDIVILLE et al., 2003).

O critério maior de diagnóstico baseia-se no achado histológico de pelo menos 15 infiltrados de mastócitos densos na MO ou nos outros órgãos extra cutâneos; enquanto os critérios menores são: morfologia anormal dos mastócitos extra cutâneos, triptase sérica $>20 \mathrm{ng} / \mathrm{ml}$ e expressão de CD2 e/ou CD25 dos mastócitos da MO e detecção de mutação no gene KIT nos órgãos extracutâneos (ANDERSEN et al., 2012).

\subsubsection{Síndromes Mieloproliferativas Não-Classificáveis (SMNC)}

Segundo a OMS, existem algumas doenças que não se encaixam nos padrões para as outras síndromes mieloproliferativas, sendo então denominadas de Síndromes Mieloproliferativas Não Classificáveis (VASSALLO; MAGALHÃES, 2003; CHAUFFAILLE, 2010).

Entre as SMNC, ressalta-se devido sua evolução extremamente agressiva a síndrome mieloproliferativa 8p12, identificada como uma leucemia de células tronco/linfoma (EMS). É uma condição relativamente rara, caracterizada na sua forma típica pela ocorrência simultânea ou sequencial de um BCR-ABL negativo, um 
transtorno mieloproliferativo, a presença de eosinofilia e um linfoma, casualmente um linfoma linfoblástico T percussor (BOYER et al., 2004).

Geneticamente a doença é definida pela fusão do gene FGFR1 (8p11) com genes associados como consequência de translocações cromossômicas. Cerca de doze genes foram identificados nessa mieloproliferação, sendo eles: ZNF198/ ZMYM2 (13q12), FGFR1OP (6q27), CEP110 (9q33), BCR (22q11), NUP98 (11P15), HERVK (19q13), FGFR10P2 (12p11), TRIM24 (7q34), MYO18A (17q23), CPSF6 (1215), LRRF1P1 (2q37) e TPR (1q25). A translocação mais comum encontrada em cerca de $50 \%$ dos casos com EMS foi a T $(8 ; 13)$ (p11;q12) ZMYM2-FGFR1. Qualquer gene parceiro provoca a ativação constitutiva de várias vias efetoras incluindo a STAT1 e STAT5, PI3K, PLC-y e MAP-quinase. Isso culmina em uma irregular proliferação neoplásica e transformação de células hematopoiéticas (RAHMAN et al., 2015).

A doença é agressiva e rapidamente se transforma em leucemia mieloide aguda. Quando identificada como uma síndrome por volta dos anos 90 foram incluídos casos aos quais se conheciam ambos critérios clínicos e citogenéticos, cujo a translocação envolvia 8p11-12 (FGFR1) e geralmente 13q11-12, bem como uma síndrome mieloproliferativa atípica diagnosticada simultaneamente com ou em estreita relação temporal com um linfoma de células $T$ imaturo. Exceto para pacientes que ocasionalmente sofreram transplante de medula óssea ou célula tronco periférico esses pacientes geralmente desenvolveram e sucumbiram para leucemia mieloide aguda. O distúrbio é ofensivo e a sobrevida é muito curta beirando os 12 meses (LI, FENG, 2012; OLABODE et al., 2014; MALLI, 2016). 


\section{Resultado e Discussão}

As Síndromes Mieloproliferativas Crônicas têm como característica a proliferação clonal de uma célula progenitora. Há diversos fatores envolvidos e continuamente sendo estudados, porém sabe-se que a desregulação gênica tem um papel importante para propiciar esses distúrbios.

Historicamente, as SMPCs foram definidas como um grupo de neoplasias com muitas semelhanças clínicas que dificultavam a diferenciação entre elas, retardando, muitas vezes, o diagnóstico ou ainda gerando uma avaliação equivocada dos pacientes. Desde então, muitos estudos já relataram a presença de inúmeras alterações no DNA capazes de gerar uma desordem gênica alterando as vias de sinalização da proliferação celular normal culminando em um processo clonal crônico.

Atualmente, com o avanço da tecnologia em biologia molecular e o alavancar na área do diagnóstico molecular muito enfoque tem sido dado em busca de alterações gênicas que possam elucidar doenças malignas a fim de gerar uma precisão no diagnóstico, fato que infere diretamente sobre o prognóstico e qualidade de vida do paciente.

Como resultado da análise das mutações identificadas nesta pesquisa foi estabelecido um painel de mutações (Apêndice 1) integradas e correlacionadas para as SMPCs, estabelecendo um documento inovador que fornece uma visão ampla sobre a abordagem fisiopatológica envolvida nessas síndromes.

O início do rastreio para identificação das SMPCs baseia-se na cariotipagem em busca da presença do cromossomo Philadelphia e na pesquisa molecular pelo gene híbrido BCR-ABL. A partir desse marcador molecular, as SMPCs são divididas em dois grandes grupos: as BCR-ABL positivas (cromossomo Philadélfia positivo) e BCR-ABL negativas (cromossomo Philadélfia negativo).

Em mais de $90 \%$ dos casos de Leucemia Mielóide Crônica há a presença do BCR-ABL positivo, sendo que a fusão desses genes promotores originam uma proteína citoplasmática chamada p210 responsável pela repercussão clínica da doença. Por esse motivo, a LMC é utilizada como diagnóstico de exclusão para as SMPCs. Entre as demais SMPCs, a Leucemia Neutrofílica Crônica também apresenta a presença do BCR-ABL positivo, contudo, nessa desordem a quebra do cromossomo Ph é diferente da LMC clássica, gerando uma proteína diferente cujo nome é p230 (MARTINS, 2016). 
A ausência do BCR-ABL positivo leva a procura de outras anormalidades, como a presença de JAK2 positiva para caracterização das demais síndromes. Assim, em casos de BCR-ABL negativo, a busca pela mutação na JAK2 torna-se um excelente marcador molecular, também dividindo àquelas que são JAK positivas para a mutação JAK2V617F daquelas JAK2 negativas para essa mesma alteração. Entre as JAK2 positivas encontra-se distribuídos a maior parte dos casos de PV, TE e MP. Assim, no grande grupo das denominadas JAK2+ ocorre uma mutação pontual que altera a codificação dessa proteína, promovendo a sua autofosforilação constitutiva e também do fator STAT5 na ausência de eritropoetina. Pode-se encontrar ainda a correlação do gene LNK com as quatro grandes SMPCs com a presença ou não da associação com a JAK2V617F.

Quando a Policetemia Vera é negativa para JAK2V617F pode se considerar uma alteração no éxon 12 da JAK2, englobando a substituição, duplicação ou substituição de nucleotídeos. O diagnóstico desse grande grupo é em sua grande maioria das vezes feito por critérios de exclusão estabelecidos segundo OMS. Quando a Mielofibrose Primária e a Policetemia Vera apresentam JAK2- pode se encontrar mutações no códon 515 no gene MPL. De outra forma, na MP a ausência de JAK2 e MPL sugere uma terceira mutação, a mutação do gene caltireticulina (CARL) que pode ser identificada em 20 a $25 \%$ dos pacientes (SILVER, 2008).

Em caso de negatividade para JAK2 e MPL na Trombocitemia Essencial podese associar mutações no gene TET2+ promovendo um rearranjo no cromossomo 4q24. Diversos genes são citados como possíveis responsáveis pelo surgimento da TE em caso de JAK2- E MPL-, dentre eles os genes: SESN2 (P87S), NTRK1 (N323S), ST13 (Q349*), O ABCB5 (G365V), FRG1 (C205Y), ASNS (D118V), TOP1MT (S479L) e DNAJC17 (A292P) (TAPPER et al., 2015). Entretanto, ainda existe uma necessidade de maiores estudos que esclareçam a real contribuição de cada um deles na fisiopatologia da doença, estratificando o prognóstico e a correlação entre os mesmos como agravo da manifestação clínica.

A mastocitose sistêmica tem como característica a mutação no códon D816V do gene KIT que é um grande responsável pela diferenciação dos mastócitos, sendo que um este um dos critérios de diagnóstico para a neoplasia. Na Leucemia Eosinofilica Crônica as causas comuns são as anormalidades nos genes dos receptores do tipo alfa e beta para o fator de crescimento derivado de plaquetas (PDGRFa e PDGFRß) ou dos receptores de fator de crescimento de fibroblastos 
(FGFR1). O rearranjo mais frequente se dá pela deleção do gene $\mathrm{CHIC2}$ ocasionando a fusão de fatores (FIP1L1/PDGRFa), outra fusão com significativa relevância é a PDGFRB-ETV6 (CHAUFFAILLE, 2010b).

Na Síndrome Hipereosinofílica Crônica a causa mais comum é a fusão FIP1L1-PDGFRA e na maioria das vezes o diagnóstico é feito por exclusão das outras síndromes. A Síndrome Mieloproliferativa 8p12 é BCR-ABL negativa causada pela fusão de vários pares de genes dentre eles ZNF198/ ZMYM2 (13q12), FGFR1OP (6q27), CEP110 (9q33), BCR (22q11), NUP98 (11P15), HERVK (19q13), FGFR10P2 (12p11) e TRIM24 (7q34), o gene cujo se fusionará com outros respectivos é o FGFR1 (8p11) (RAHMAN et al., 2015).

Vale ressaltar que estudos em busca por novas mutações devem continuar em expansão a fim de elucidar os possíveis casos das SMPCs reconhecidos atualmente como Síndromes Mieloproliferativas Não-Classificáveis. 


\section{Considerações Finais}

A análise documental demonstra que apesar de compartilharem de semelhantes características fisioclínico-patológicas, as Síndromes Mieloproliferativas Crônicas definitivamente não partilham das mesmas mutações, responsáveis essas pelas individualidades e particularidades de cada distúrbio.

Os resultados corroboram com pesquisas anteriores uma vez que esclarecem a importância molecular e genética na caracterização de cada uma das patologias com a finalidade de promover um diagnóstico mais claro, amplo, especifico e seguro. Observou-se também a relevância da caracterização gênica a partir de moléculas que quando presentes se associam a um perfil clínico diferenciado.

As SMPCs possuem incidência baixa quando comparadas a outras doenças neoplásicas, fato que dificulta estudos mais extensos nessa área. Dessa forma, pesquisas que objetivam analisar um perfil epidemiológico são escassas e por meio disso encontra-se a dificuldade de formação de grupos de estudos que visem uma investigação completa. Os genes BCR-ABL fusionados são ainda o critério de inclusão e exclusão para diagnose das Síndromes Mieloproloferativas Crônicas e o ponto de partida para a identificação inicial de um caso de SMPC. Outro marcador molecular que se destaca como critério de diagnóstico segundo a OMS é a pesquisa da JAK2 responsável pela maioria dos casos de SMPCs quando BCR-ABL negativas.

A realização de um perfil molecular completo tem como desvantagem o alto custo das técnicas moleculares, contudo, fornece uma ferramenta complementar ao diagnóstico, podendo evitar casos investigados de forma errônea ou ainda favorecendo a identificação de casos em uma fase precoce da evolução. Ressalta-se ainda que a esquematização das mutações através de um painel colabora, simplifica e facilita o acesso às informações e pode ser usado para embasamento de pesquisas futuras. 


\section{Referências Bibliográficas}

AHMED A, CHANG CC. Chronic idiopatic myelofibrosis: clinicophatologic features, pathogenesis, and prognosis. Arch Pathol Lab Med. V.130, n.8, p.1133-43.

AMARAL, C. B. A. Policetemia vera - caracterização clínica e molecular e novas abordagens terapêuticas. Dissertação (Mestrado) do Ciclo de Estudos de Mestrado Integrado em Medicina - Universidade de Coimbra, Coimbra, 2009.

ANDERSEN et al. Systemic mastocytosis - a systematic review. Danish Medical Journal, Copenhagen, v. 59, n. 3, p. 1-6, 2012.

ARORA B et al. Peripheral blood CD34 count in myelofibrosis with myeloid metaplasia:

a prospective evaluation of prognostic value in 94 patientes. $\mathbf{B r} \mathbf{J}$ Haematol. V.128, n.12, p.42-8, 2005.

BARBUI, T et al. Philadelphia-negative classical myeloproliferative neoplasm: critical concepts and management recommendations from european leucemia net. Journal clinical oncology, 29:761-9, 2011.

BAROSI G et al. Diagnostic and clinical relevance of the number of circulating CD34(+) cells in myelofibrosis with myeloid metaplasia. Blood. V.98, n.12, p.3249-55, 2001.

BAROSI G, HOFFMAN R. Idiopathic myelofibrosis. Semin Hematol. V.24, n.4, p.24858, 2005.

BEER PA et al. How I treat essential thrombocythemia. Blood, v.117, n.5, p.1472-89, 2011.

BITTENCOURT, R. I. el al. Tombocitose essencial: o que é essencial saber. Revista Brasileira de Hematologia e Hemoterapia, São Paulo, v. 32, n. 2, p. 162-170, 2010. BORTOLHEIRO, T. C.; CHIATTONE, C. S. Leucemia Mielóide crônica: história natural e classificação. Revista Brasileira de Hematologia e Hemoterapia, São Paulo, v. 30, suppl.1, p. 3-7, 2008.

BOYER J. t(8;9)(p12;q33) CNTRL/FGFR1. Atlas Genet Cytogenet Oncol Haematol. v.8, n.2, p.9-93, 2004. 
BOYIADZIS, M; FRAME, J; KOHLER, D; FOJO, T. Hematology-oncology Therapy, 2 ed. USA: New York, Mc Graw Hill, 2007.

BRIÈRE J B. Essential thrombocythemia. Orphanet J Rare Dis. 2007.

BUZZAS, C et al. Budd Chiari syndrome secondary to polycithemia vera, Journal of gastrointestinal and liver diseases, romenia, 18(3):363-6.

CERVANTES F. Management of essential thrombocythemia. Hematology. Am Soc Hematol Educ Program. P.215-21, 2011.

CHAITER, $Y$ et al. High incidence of myeloproliferative disorders in ashkenazi jews in nothern israel. Leukemia and lymphoma journal, v.7, p. 251-255, 2009.

CHAUFFAILLE, M. L.L.F. Análise citogenética e FISH no monitoramento da LMC em tratamento com inibidores da tirosino quinase. Revista Brasileira de Hematologia e Hemoterapia, São Paulo, v. 30, suppl. 1, p. 13-19, 2008.

CHAUFFAILLE, M. L.L.F. Eosinofilia reacional, leucemia eosinofílica crônica e síndrome hipereosinofílica idiopática. Revista Brasileira de Hematologia e Hemoterapia, São Paulo, v. 32, n. 05, p. 395-401, 2010 b.

CHAUFFAILLE, M. L.L.F. Neoplasias mieloproliferativas: revisão dos critérios diagnósticos e dos aspectos clínicos. Revista Brasileira de Hematologia e Hemoterapia, São Paulo, v. 32, n. 4, p. 308-316, 2010 a.

CHEN, Yan et al. "The Polymorphisms in LNK Gene Correlated to the Clinical Type of Myeloproliferative Neoplasms." Ed. Connie J Eaves. PLoS ONE 11.4 (2016): e0154183. PMC. Web. 25 Aug. 2017.

CHUSID M. J., et al.. The hypereosinophilic syndrome: analysis of fourteen cases with review of the literature. Revista Medicine (Baltimore), Hagerstown, v. 54, n. 1, p.1-27, 1975.

COOLS, J. et al. A tyrosine kinase created by fusion of the PDGFRA and FIP1L1 genes as a therapeutic target of imatinib in idiopathic hypereosinophilic syndrome. New England Journal of Medicine, Boston, v. 348, n. 13, p. 1201-1214, 2003.

DI RAIMONDO F et al. Elevathed vascular endotelial growth fator (VEGF) sérum levels in idiopathic myelofibrosis. Leukemia.v.15, n.6, p.976-80, 2001. 
DUARTE, A. M. M., et al.. Síndrome hipereosinofílica: revisão de literatura. Revista Disciplinarum Scientia, Santa Maria, v. 13, n. 2, p. 265-274, 2012.

DUARTE, N. L. A leucemia mieloide crônica e o uso de mesilato de imatinibe em seu tratamento. Monografia (Graduação) do Curso técnico de nível médio em laboratório em Biodiagnóstico em saúde - Fundação Oswaldo Cruz, Rio de Janeiro, 2005.

EUROPEAN UNION. Leucemia eosinofílica crónica (LEC) y otros síndromes hipereosinofílicos. Disponível em: <http://empendium.com/manualmibe/chapter/B34.II.15.9>. Acesso em: 20 abr. 2016. FERNANDES, E. I. et al. Mastocitose sistêmica na infância: relato de 3 casos. Jornal de Pediatria, Rio de Janeiro, v. 78, n. 2, p. 176-180, 2002.

GRATTAN CEH, BLACK AK. Urticaria and mastocytosis. In: Burns T, Breathnach S, Cox. N, Griffiths C, editors. Rook's textbook of dermatology. 7th ed. Oxford: Blackwell Science; 2004. v.3. p.31-7

GRIESSHAMMER, M. et al.Essencial thrombocythemia - clinical significance, diagnosis and treatmente. Dtsch Arztebl Internacional, Cologne, v. 104, p. 34-35, 2007.

GRUPO ITALIANO STUDIO POLICETEMIA (GISP). Policetemia vera: the natural history of 1213 patients followed over 20 years. Ann Int Med. P.656-64, 1995.

HAMERSCHLAK, N. Leukemia: genetics and prognostic factors. Jornal de Pediatria, Porto Alegre, v. 84, n. 4, suppl. 0, p. 52-57, 2008.

INCA. Leucemia mielóide crônica. Revista Brasileira de Cancerologia, Rio de Janeiro, v. 49 , n. 1 , p. $5-8,2003$.

JAMES, $C$ et al. A unique clonal JAK2 mutation leading to constutive signalling causes polycithaemia vera, Internacional weekly journal of Science nature, p.1144-1148, 2005.

JAMES, C. The JAK2V617 mutation in polycythemia vera and other myeloproliferative disorders: one mutation for three diseases? American Society of Hematology, Washington, v. 69, n. 1, p. 69-75, 2008. 
JANOWSKA- WIECZOREK E et al. Growth factors and cytokines upregulate gelatinase expression in bone marrow CD34+ cells and their transmigration through reconstituted basement membrane. Blood. V.93, n.10, p.3379-90, 1999.

JOHANSSON P. Epidemiology of the mieloproliferative disorders polycytemia vera and essencial thrombocythemia. Semin Thromb Hemost. P.171-3, 2006.

JUNIOR, I. R. Síndrome hipereosinofílica idiopática. Relato de caso e revisão de literatura. Revista da Sociedade Brasileira de Clínica Médica, São Paulo, v. 8, n. 2, p. 177-182, 2010.

LASHO TL et al. SRSF2 mutations in primary myelofibrosis: significant clustering with IDH mutations and independent association with inferior overall and leukemia-free survival. Blood. V.120, n.20, p.4168-4171, 2012.

LEE, G; ARCASORY, M, The clinical and laboratory evaluation of the patient with erythrocytosis. European Internacional Journal, v.26, p.297-302, 2015.

LEVINE, R. L.; GILLILAND, G. Myeloproliferative disorders. American Society of American, Washington, v. 112, n. 6, p. 2190-2197, 2008.

LI, FENG. Identification of a novel partner gene, TPR, fused to FGFR1 in 8p11 myeloproliferative syndrome. Genes Chromosom. Cancer. V.51, p.890-897, 2012.

MALLI T et al. Functional Characterization, Localization, and Inhibitor Sensitivity of the TPR-FGFR1 Fusion in 8p11 Myeloproliferative Syndrome. GENES, CHROMOSOMES \& CANCER. V. 55, p. 60-68, 2016.

MARTYRE MC et al. Elevated levels of basic fibroblast growth fator in megakaryocytes and platelets from patients with idiophatic myelofibrosis. Br J Haematol. V.97, n.2, p.441-8, 1997.

MASSA M et al.. Circulating CD34+, CD133+, and vascular endotelial growth fator receptor 2-positive endotelial progenitor cells in myelofibrosis with myeloid metaplasia. J Clin Oncol. V.23, n.24, p.5688-95, 2005.

METCALFE DD et al.. The mastocytosis syndrome. Dermatology in general medicine. 6th ed. New York: McGraw-Hill; v.2, p.1902-8, 2003. 
MICHIELS JJ et al.The paradoxi of platelet activation and impaired fuction: plateletvon willebrand fator interactions, and the etiology of thrombocythemia and polycethemia vera. Semin Thromb Hemost. P.589-604, 2006.

MONTE-MÓR, B. C. R.; COSTA, F. F. A mutação JAK2 V617F e as síndromes mieloproliferativas. Revista Brasileira de Hematologia e Hemoterapia, São Paulo, v. 30, n. 3, p. 241-248, 2008.

MOURA, L. G. Expressão de galectinas 1 e 3 em neoplasias mieloproliferativa. Dissertação (Mestrado) do Programa de Pós-graduação em Biociências Aplicadas à Farmácia - Universidade de São Paulo, São Paulo, 2012.

NANGALIA $J$ et al. Somatic CARL mutation in myeloproliferative neoplasms with nonmutated JAK2. N Engl J Med. V.369, n.25, p.2391-2405, 2013.

NORD. The physician's guide to myelofibrosis. Disponível em: <nordphysicianguides.org/myelofibrosis/>. Acesso em: 11 de abr. 2016.

OLABODE J et al. The 8p12 myeloproliferative syndrome. Nigerian Medical Journal. V. 55, n.2, p.176-179, 2014.

PRENDIVILLE JS, KROL AL. Mastocytosis. In: Schachner LA, Hansen RC. Pediatric dermatology. 3rd ed. St Louis (Mo): Mosby: p.753-9, 2003.

QUINTERO, M. V. Leucemia neutrofílica crónica con tetrasomía 8. Revista Colombiana de cancerologia, Santafé de Bogotá, v. 8, n. 2, p. 40-44, 2004.

RAHMAN K et al. 8p11 myeloproliferative syndrome: A case reportof this rare clinical entity. Indian journal of pathology and microbiology . v.58. n.2, p.254-255, 2015.

REILLY JT. Idiopathic myelofibrosis: Pathogenesis to treatment. Haematol Oncol, v.24, n.2, p.56-63, 2006.

RIBEIRO $J$ et al. Duas classes de mutação na evolução de Policetemia vera para leucemia mieloide aguda. Revista brasileira de hemoterapia e hematologia. São Paulo, v. 31, n.2, p.115-117, 2009.

SANTOS, A., LOUREIRO, C., CHIEIRA, C. Síndrome hipereosinofílica idiopática: Um caso clínico. Revista Portuguesa de Imunoalergologia, Portugal, v. 16, n. 1, p. 93105, 2008. 
SCHMIT A et al. Polymorphonuclear neutrophil and megakaryocyte mutual involvement in myelofibrosis pathogenesis. Leuk Lymphoma. v.43, n.4, p.719-24, 2002.

SOUTO, E. Leucemia Neutrofílica Crônica. Diagnósticos da América. Disponível em:<http://webmail.diagnosticosdaamerica.com.br/ISO9000/DELBONI/ConhecMedic o.nsf/All/BCFE387BC419FB82832574B0007ABE3C?OpenDocument>. Acesso em: 14. abr. 2016.

SPIVAK, J. L.; SILVER, R. T. The revised World Health Organization diagnostic criteria for polycythemia vera, essential thrombosis, and primary myelofibrosis: an alternative proposal. American Society of American, Washington, v. 112, n. 2, 231 239, 2008.

TAPPER W et al. Genetic variation ate MECOM, TERT, JAK2 and HBS1L-MYB predisposes to myeloproliferative neoplasm. Nature Communications, 2015.

TEFFERI, A. Essential thrombocyhemia: scientific advances and current practice. Curr Opin Hematol. n.3, p.93-8, 2005.

TEFFERI, A. Pathogenesis of myelofibrosis with myeloid metaplasia. Jornal of Clinical Oncology, Rochester, v.23, 2005

TEFFERI, A. The history of myeloproliferative disorders: before and after Dameshek. Leucemia Society of America, Baltimore, v. 22, p. 3-13, 2008.

VAINCHENKER $W$ et al. New mutation and pathogeneis of myeloproliferative neoplasm. Blood. V.118, n.7, p.1723-35, 2011.

VAKIL E, TEFFERI A. BCR-ABL1-negative myeloproliferative neoplasm: a review of molecular biology, diagnosis, and treatment. Clin Lymphoma Myeloma Leuk, 2011.

VASSALLO, J.; MAGALHÃES, S. M. M. Síndromes mielodisplásicas e mielodisplásicas/mieloproliferativas. Revista Brasileira de Hematologia e Hemoterapia, São Paulo, v. 31, n. 4, p. 267-272, 2003.

XU M et al. Constitutive mobilization of CD34+ cells into the peripheral blood in idiophatic myelofibrosis may be due to the action of a number of proteases. Blood. V.105, n.11, p.4508-15, 2005. 
YANG $\mathrm{H}$ et al.. Single-Cell Exome Sequencing and Monoclonal Evolution of a JAK2Negative Myeloproliferative Neoplasm. Cell 148, 873-885, 2012.

ZAGO. M. A.; FALCÃO, R. P.; PASQUINI, R. Hematologia - fundamentos e prática. São Paulo: Editora Atheneu, 2004. 


\section{Apêndice}

7.1 Apêndice 1 - Painel da mutações para as Síndromes Mieloproliferativas Crônicas

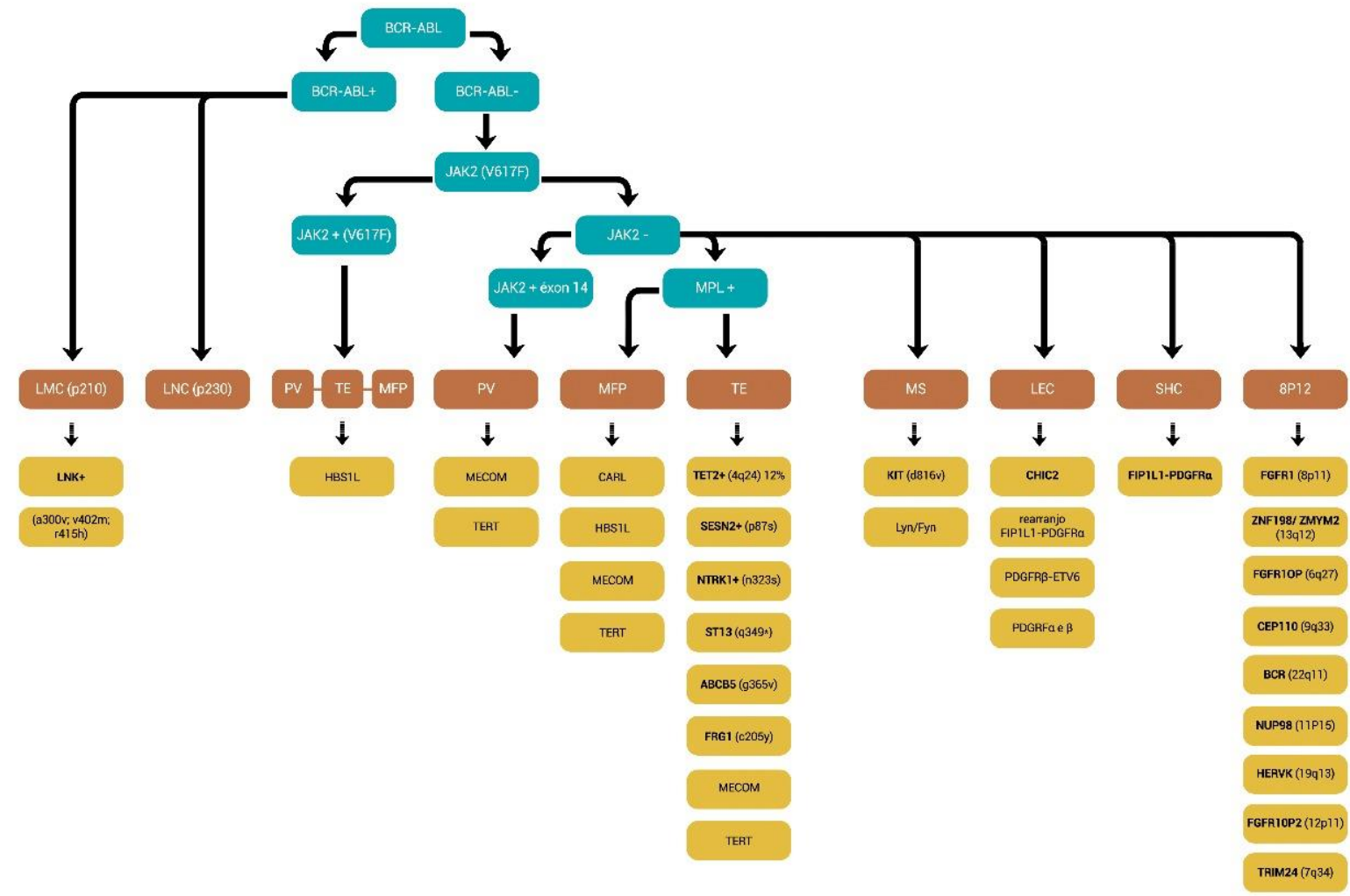

